\title{
Temačni turizem
}

\author{
Metod Šuligoj \\ uP Fakulteta za turistične študije - Turistica \\ metod.suligoj@fts.upr.si
}

\section{Uvod}

Turistične destinacije se pri razvoju ponudbe navezujejo na različne tematske sklope, kar obravnavamo kot tematski turizem. Znotraj tega se z razvojem novih specifičnih turističnih produktov ustvarjajo tudi niše; tematski turizem se sicer ne enači z nišnim turizmom. Sodobni tematski turizem ne sloni na novo »izumljeni« obliki turizma, ampak se z novim konceptom (ali z novimi koncepti) vključuje v nadaljnji razvoj destinacije. Njegova kakovost ni odvisna zgolj od posameznega tematskega sklopa, temveč od celotnega turizma v regiji/destinaciji in širše (Đurašević, 2014). Vse to je skladno tudi s pogledi Svetovne turistične organizacije (World Tourism Organization, 1985) o turizmu posebnega pomena, ki se je kot tematski turizem pojavil v osemdesetih letih 20. stoletja. Na začetku je bil ta turizem sicer precej ozko zastavljen in je bil namenjen samo specializiranim ciljnim skupinam, vendar se je kaj kmalu razširil še na druga, manj specializirana področja (Ali-Knight, 2011). Danes ga razumemo kot del interdisciplinarnega sistema, ki ga na dveh ravneh, lokalni in globalni, zaznamujejo številni elementi (tehnološki, politični, ekonomski, kulturni, ekološki, družbeno-kulturni in socialno-ekonomski) in je v 
21. stoletju močno zaznamovan z mediji (Trauer, 2006). V tem kontekstu obravnavamo tudi t.i. temačni turizem (angl. dark tourism), ki je povezan z vojaškimi konflikti, nasiljem pa tudi naravnimi katastrofami, ki povzročajo smrt in trpljenje.

Vojne in drugi nasilni konflikti puščajo v okolju, ki ga prizadenejo, dolgoročne (trajne) posledice. Čeprav morda zveni paradoksalno, takšno okolje vsekakor ponuja vrsto možnosti za razvoj turizma. V tem smislu imajo destinacije na postkonfliktnih območjih dve možnosti turističnega razvoja. Prva: takšna destinacija lahko ponovno ustvarijo imidž, kot ga je destinacija imela pred konfliktom, ter "pozabijo« na obdobje konflikta - takšen je primer Dubrovnika. Primer Sarajeva pa kaže na drugo možnost, to je, da destinacija posledice (vojaškega) konflikta vključi v turistično ponudbo. Seveda je takšnih primerov na vseh poseljenih celinah veliko - glej preglednice 3.1, 3.2 in 3.3. V tem primeru govorimo o t.i. temačnem turizmu (Wise in Mulec, 2014), ki je tudi glavni predmet obravnave v tem poglavju. Cilj poglavja je predstaviti področje temačnega turizma v nacionalnem (slovenskem) in mednarodnem merilu ter se pri tem naslanjati na vrste/tipe, ki so jih opredelili domači in tuji raziskovalci te specifične oblike turizma. $\mathrm{V}$ tem pogledu so v nadaljevanju izpostavljene tudi različne perspektive, kjer niso spregledani niti različne kontroverze in pomisleki.

\section{Definicije, koncept in vrste temačnega turizma}

Vojaški konflikti, kot tudi mnogi z nasiljem zaznamovani totalitarni režimi, so s svojimi (tragičnimi) posledicami omogočili oblikovanje številnih spominskih praks in tudi s tem povezana potovanja. Seveda pa današnji obiskovalci ne iščejo zgolj tovrstnih primerov, povezanih s smrtjo in trpljenjem, ampak tudi posledice naravnih nesreč, terorističnih napadov in sorodnih kriminalnih dejanj kot tudi kraje poslednjega počitka (predvsem v primeru poznanih/slavnih oseb s področja kulture ali politike). Čeprav ima ta posebna oblika turizma očitno globoke korenine v izročilu človeštva, jo vseeno razumemo kot sodoben turistični produkt, ki množično (organizirano) privablja pozornost obiskovalcev, predvsem pa raziskovalcev, šele od konca 20. stoletja dalje (Seaton, 2018). Seveda ne gre zanemariti dejstva, da so tudi npr. gladiatorski boji, sežiganje čarovnic in druge eksekucije obiskovalce privabljale že prej. Kot dva ključna dogodka/konflikta $v$ začetnem razvoju temačnega turizma obravna- 
vamo mednarodni spopad pri Waterlooju leta 1816 (Knox, 2006; Seaton, 1999; Smith, 1998) in polom Napoleona, ki je sprožil obiskovanje tega kraja spopada v sledečih letih in je še danes zelo poznana tematska turistična točka Belgije. Množično obiskovanje grobišč in ogled prizorišč spopadov pa sta se pravzaprav začela šele po "veliki vojni« (Kavrečič, 2017; Šuligoj, 2016a; Winter, 2009a; 2009b; 2011), ki zaradi obsega in tragičnih posledic še danes predstavlja pomemben element turistične ponudbe v mnogih evropskih državah, npr. v Sloveniji, Italiji, Franciji, Belgiji, Poljski, Bosni in Hercegovini itd. Resno znanstveno preučevanje tega turističnega fenomena se je začelo šele v drugi polovici devetdesetih let 20. stoletja (Light, 2017; Seaton, 2018). To je sprožilo številne različne perspektive in s tem tudi različno poimenovanje ter definicije te oblike turizma:

- turizem črnih točk (angl. black spot), kar Rojek (1994) opiše kot trženje območij, na katerih so se znane osebnosti ali večje število ljudi srečali z nenadno in nasilno smrtjo,

- tanaturizem (angl. thanatourism) je "potovanje, katerega motiv je delno ali v celoti želja po dejanskem ali simbolnem srečanju s smrtjo, predvsem, vendar ne izključno, z nasilno smrtjo « (Seaton, 1996, str. 15);

- turizem grozodejstev (angl. atrocity tourism) je vrsta turizma, ki posameznika vodi k obisku prizorišč holokavsta (Beech, 2000; Tunbridge in Ashworth, 1996);

- morbidni turizem (angl. morbid tourism) je "potovanje k znamenitostim, ki so osredotočene na nesreče in nenadno nasilno smrt« (Blom, 2000, str. 26); in

- temačni turizem (angl. dark tourism) je "pojav, ki zajema predstavitev in porabo (obiskovalcev) resničnih in uprizorjenih krajev smrti in tragedij« (Foley in Lennon, 1996, str. 198). Tarlow (2005, str. 48) trdi, da je temačni turizem »obiskovanje krajev, kjer so se zgodile tragedije ali nevsakdanje smrti, ki še vedno vplivajo na naša življenja", medtem ko Gibson (2006, str. 47) to enostavno definira kot "turizem, ki vključuje lokacije, povezane s smrtjo in hudim trpljenjem«. Verjetno je še najbolj sprejeta splošno definicija Stona (2006, str. 146), da gre za "potovanje h krajem, povezanim s smrtjo, trpljenjem in z navidezno mračnostjo«.

Zgoraj navedeni pojmi so morda najbolj znani, niso pa edini. Na 
tem mestu je potrebno navesti še nekaj drugih, ki jih zasledimo $\mathrm{v}$ mednarodnem prostoru (navedeni so v svoji izvorni obliki brez prevoda): sombre tourism (Butcher, 2003), fright tourism (Bristow in $\mathrm{Ne}-$ wman, 2005), grief tourism (Dunkley idr., 2007), conflict heritage tourism (Mansfeld in Korman, 2015), genocide tourism (Dunkley idr., 2007), trauma tourism (Clark, 2006), war-related tourism (Bigley idr., 2010), post-war tourism (Wise, 2011), war tourism (Keyes, 2012), warfare tourism (Šuligoj, 2016b; 2017), battlefield tourism (Dunkley idr., 2011), tourism of memory (Hertzog, 2012) ali memorable tourism (Drvenkar idr., 2015). Ta pojmovna raznolikost dokazuje, da je raziskovalno področje še vedno v neki zgodnji razvojni fazi, saj je potreba po jasni definiciji še vedno zelo prisotna (Stone in Sharpley, 2008, str. 575; Young in Light, 2016, str. 68). Če pogledamo dejansko ponudbo temačnega turizma, opazimo precejšnjo raznolikost, ta pa je vidna tudi pri zapletenejših znanstvenih obravnavah te tematike. Glede na tematiko, motive obiskovalcev in pojavnost je mogoče definirati več različnih vrst tovrstnega turizma. A. P. Fonseca idr. (2016) trdijo, da splošna akademska klasifikacija temačnega turizma temelji na njegovi privlačnosti in motivih za obisk ter obsega:

- turizem vojne in bojišč (obiskovanje vojnih prizorišč z namenom turističnega ogleda in izobraževanja);

- turizem katastrof (obiskovanje in ogledovanje krajev, kjer so se zgodile naravne ali druge katastrofe);

- zaporniški turizem (zapori s temačno preteklostjo z namenom izobraževanja ali zabave so lahko pomemben del tematske turistične ponudbe);

- pokopališki turizem (obiskovanje pokopališč v želji po ogledu umetniških del in okrasja na grobovih znanih ali neimenovanih ljudi ter s tem povezano izobraževanje); ${ }^{1}$

- turizem duhov (obiskovanje točk, kjer naj bi se prikazovali duhovi, bodisi za spiritualne, poučnozgodovinske ali zabaviščne namene);

- turizem holokavsta (obiskovanje krajev, kjer so se odvijali predvsem množični poboji, ki obiskovalce opominjajo na napake, storjene v preteklosti).

1. Pri pokopališkem turizmu je potrebno izpostaviti tudi obiskovanje grobov/grobnic/mavzolejev znanih oseb, kar je lahko glavni motiv obiska (ne glede na umetniško vrednost umetniških del in okrasja). 
Seaton (1996), ki je eden najbolj uveljavljenih raziskovalcev temačnega turizma, predlaga razvrstitev dejavnosti temačnega turizma $\mathrm{v}$ pet kategorij:

- potovanje z namenom prisostvovanja javnim usmrtitvam;

- potovanje na prizorišča smrti posameznikov ali množic po tem, ko so se te že zgodile;

- potovanje k spomenikom ali krajem poslednjega počitka;

- potovanje z namenom ogleda dokazov o smrti ali njenih simboličnih predstavitev na sicer s smrtjo nepovezanih mestih;

- potovanje na kraje ali prireditve ponovnega uprizarjanja oz. simulacije smrti.

Zanimiva je tudi tipologija A. Kendle (2008), ki je v veliki meri tudi odsev sodobnih problemov, kot so vojne, revščina, brezup ter podnebne spremembe:

- turizem žalovanja (angl. grief tourism) vključuje obiskovanje prizorišč tragičnih dogodkov, npr. koncentracijskih taborišč, bivših bojišč, pokopališč, krajev tragičnih dogodkov ali zločinov;

- turizem katastrof (angl. disaster tourism) zajema obiskovanje krajev velikih naravnih katastrof; ${ }^{2}$

- turizem revščine (angl. poverty tourism) zajema obiskovanje prizorišč velike revščine, npr. favele, slumi; ${ }^{3}$

- samomorilni turizem (angl. suicide tourism) se pojavlja v dveh oblikah: (a) potovanje na določeno destinacijo z namenom samomora, (b) potovanje v države, kjer je dovoljena evtanazija, npr. v Belgiji, na Nizozemskem in v Švici;

- turizem sodnega dne (angl. doomsday tourism) obsega potovanja na destinacije/kraje, ki bi jih bilo potrebno obiskati, ker so

2. To lahko ustvarja oviro/motnjo pri vzpostavljanju normalnega življenja v prizadetih skupnostih, po drugi strani pa ponuja možnost priliva denarja zaradi potrošnje obiskovalcev. Vodstva destinacij pa lahko te pretekle travmatične izkušnje namerno pahnejo v pozabo $\mathrm{z}$ namenom, da destinacija ne bi pridobila slovesa nevarne destinacije, npr. Posočje v Sloveniji in sever Italije kot potresno ogroženi območji, Dalmacija kot požarno ogroženo območje in Florida kot območje, ki ga ogrožajo orkani/tornadi. Nekatera v preteklosti prizadeta (in do neke mere še vedno nevarna) območja pa lahko postanejo celo izjemno atraktivna, npr. območja z vulkani v južni Italiji.

3. Paradoksalno je, da če bi na ta način izboljšali oz. odpravili njihovo revščino, tovrstnega turizma na tem območju ne bi bilo več. Gre za obliko, ki je zelo kontroverzna. 
zaradi okoljskih problemov in globalnega segrevanja ogroženi (glej tudi Lemelin idr. (2010)); sicer pa je to samo po sebi škodljivo, saj prav povečan obisk na destinaciji ustvarja dodaten okoljski pritisk nanje.

Kot lahko vidimo, je temačni turizem področje z veliko protislovji, predvsem pa odsev kriznih oz. težkih in neprijetnih trenutkov v času, ko je najhuje že mimo. Pri temačnem turizmu, ki je pretežno namenjen le zahodnim turistom in njihovemu razumevanju smrti (Lennon in Foley, 2000; Seaton, 2009), se zaradi neprimernosti in izkoriščanja hitro srečamo s konflikti, pretiravanji, $\mathrm{z}$ manipulacijo, $\mathrm{s}$ kontroverzami in z drugimi problemi. Rolfes (2010) ugotavlja, da se turistična ponudba, povezana s smrtjo in trpljenjem, lahko razume kot naslajanje nad človeško nesrečo in vrsta razvedrila - S. Causevic in Lynch (2011) na primeru Bosne in Hercegovine problematizirata ravno to. Torej, sodobni temačni turizem sproža številne pomisleke in kritike. Nekateri avtorji, npr. Ashworth in Isaac (2015) ter Jamal in L. Lelo (2010), ${ }^{4}$ ugotavljajo, da nekatere tipologije niso skladne $\mathrm{z}$ bistvom (temnost, temačnost). Temnost/temačnost, ki naj bi izražala jasno povezavo s trpljenjem in smrtjo, sploh ni jasna (izrazita, logična), čeprav že same definicije temačnega turizma (tudi tanatoturizma) to jasno izpostavljajo. Tu lahko osvetlimo nekaj primerov: A. P. Fonseca idr. (2016) izpostavljajo »turizem duhov«, L. Kužnik in N. Veble (2017, str. 145-148) "paranormalni turizem» in "poučnozabavni turizem «; tudi njunih tipov, povezanih z nekdanjimi totalitarnimi režimi, ne moremo kar neposredno povezati (zgolj) s smrtjo in trpljenjem. S tem se očitki o kontroverznosti in nedefiniranosti dejavnosti/pojma (dark tourism), ki že sicer ne uživa posebne podpore v stroki in managementu (Baldwin in Sharpley, 2009; Kravanja, 2018), zgolj poglablja; temačni turizem je zgolj eden izmed konceptov, ki se ukvarja s povezavo med turizmom in smrtjo (Light, 2017, str. 280). V primeru negativnih okoljskih sprememb pa je potrebno izpostaviti, da turisti poskrbijo za pritok denarja na ogrožena območja, ampak s svojim obiskom pravzaprav ogrožajo destinacije in s tem dolgoročno zmanjšujejo prihodek (Lemelin idr., 2010).

Obisk krajev s temačno preteklostjo je eden od načinov za opredeljevanje ali potrjevanje kolektivnih identitet (Light, 2017) določenih skupnosti/narodov. Ta pomen lahko pripišemo tudi obiskovanju

4. Glej tudi Biran idr. (2011) in Light (2017). 
Preglednica 3.1 Izbrani primeri krajev in prireditev, povezanih s temačnim turizmom v Evropi

\begin{tabular}{|c|c|c|}
\hline Kraj & Država & Opis \\
\hline $\begin{array}{l}\text { Koncentracijsko } \\
\text { taborišče Au- } \\
\text { schwitz }\end{array}$ & Poljska & $\begin{array}{l}\text { Med letoma } 1940 \text { in } 1945 \text { je v celotnem kompleksu } \\
\text { taborišča umrlo več kot milijon moških, žensk in } \\
\text { otrok (ocena); taborišče postane simbol holoka- } \\
\text { vsta. }\end{array}$ \\
\hline Pompeji & Italija & $\begin{array}{l}\text { Danes eno najprepoznavnejših italijanskih tu- } \\
\text { rističnih atrakcij v bližini Neaplja je bilo uniče- } \\
\text { no med izbruhom Vezuva leta } 79 \mathrm{n} \text {. št. Umrli so } \\
\text { vsi prebivalci mesta. Danes je mesto uvrščano na } \\
\text { u Nesco-v seznam svetovne dediščine. }\end{array}$ \\
\hline $\begin{array}{l}\text { Père Lachaise, Pa- } \\
\text { riz }\end{array}$ & Francija & $\begin{array}{l}\text { Je največje in tudi najbolj obiskano pokopališče } \\
\text { v Parizu; je tudi najbolj obiskano pokopališče na } \\
\text { svetu. Na pokopališču so pokopani: Jim Morri- } \\
\text { son, Edith Piaf, Frederic Chopin, Honore de Bal- } \\
\text { zac, Oscar Wilde, Marcel Proust, Eugène Delacro- } \\
\text { ix, Max Ernst in številni drugi znani Parižani. }\end{array}$ \\
\hline $\begin{array}{l}\text { Latvijski zapor } \\
\text { Karosta - hotel in } \\
\text { muzej, Liepsja }\end{array}$ & Latvija & $\begin{array}{l}\text { To je bil večino 20. stoletja (posebej v času socia- } \\
\text { lizma) delovni zapor, danes pa služi kot muzej in } \\
\text { tematski hotel. }\end{array}$ \\
\hline $\begin{array}{l}\text { Pont de l'Alma, } \\
\text { Pariz }\end{array}$ & Francija & $\begin{array}{l}\text { V bližnjem tunelu je v prometni nesreči umr- } \\
\text { la britanska princesa Diana (1997). Ob mostu je } \\
\text { Flamme de la Liberté, ki je postal nekakšen neu- } \\
\text { radni spomenik v spomin na ta dogodek. }\end{array}$ \\
\hline $\begin{array}{l}\text { Pariške katakom- } \\
\text { be }\end{array}$ & Francija & $\begin{array}{l}\text { Podzemne kostnice hranijo ostanke približno še- } \\
\text { stih milijonov ljudi in so »največji grob na svetu«. }\end{array}$ \\
\hline Titanic Belfast & $\begin{array}{l}\text { Združeno } \\
\text { kraljestvo }\end{array}$ & $\begin{array}{l}\text { Je ena od osrednih atrakcij Severne Irske in spo- } \\
\text { menik pomorske dediščine Belfasta s tragično } \\
\text { zgodbo Titanika. }\end{array}$ \\
\hline Kostnica Sedlec & Češka & $\begin{array}{l}\text { Je majhna rimokatoliška kapela, kjer se nahajajo } \\
\text { kosti od } 40.000 \text { do } 70.000 \text { ljudi. Njihove kosti so } \\
\text { bile v mnogih primerih umetniško razporejene, } \\
\text { da so oblikovale okraske in opremo za kapelo. }\end{array}$ \\
\hline
\end{tabular}

Nadaljevanje na naslednji strani

prireditev, ki se odvijajo na teh krajih (Kennell idr., 2018), pri čemer se na ta način lahko potrjuje tudi družinska identiteta: med družinskimi člani, ki obiščejo kraj trpljenja in smrti, se oblikuje tesnejša vez, potomci pa se soočijo s spomini svojih prednikov in na sedanjost pogledajo skozi njihove oči (Fallon in Robinson, 2016). Prireditve večjih razsežnosti in s tem povezani spomeniki s časom postanejo pomembni simboli, del izjemne dediščine in kolektivnega spomi- 
Preglednica 3.1 Nadaljevanje s prejšnje strani

\begin{tabular}{|c|c|c|}
\hline Kraj & Država & Opis \\
\hline $\begin{array}{l}\text { Muzej žrtev ge- } \\
\text { nocida, Vilna }\end{array}$ & Litva & $\begin{array}{l}\text { Muzej se nahaja v nekdanji stavbi кGв, kjer so } \\
\text { Sovjeti petdeset let načrtovali in izvajali zločinska } \\
\text { dejanja. }\end{array}$ \\
\hline $\begin{array}{l}\text { Kapela kosti, } \\
\text { Évora }\end{array}$ & Portugalska & $\begin{array}{l}\text { V kapeli v sklopu cerkve Sv. Frančiška so notranje } \\
\text { stene »okrašene« s človeškimi lobanjami in kost- } \\
\text { mi. }\end{array}$ \\
\hline $\begin{array}{l}\text { Londonska je- } \\
\text { ča (The London } \\
\text { Dungeon) }\end{array}$ & $\begin{array}{l}\text { Združeno } \\
\text { kraljestvo }\end{array}$ & $\begin{array}{l}\text { Danes je to kraj, kjer se poustvarja različne krvave } \\
\text { in temačne zgodovinske dogodke, tudi v stilu čr- } \\
\text { nega humorja. }\end{array}$ \\
\hline $\begin{array}{l}\text { Pripjat, mesto } \\
\text { černobilske ne- } \\
\text { sreče }\end{array}$ & Ukrajina & $\begin{array}{l}\text { Jedrska nesreča, ki se je zgodila v Černobilu leta } \\
\text { 1986, je največja jedrska nesreča v 20. stoletju na } \\
\text { svetu. }\end{array}$ \\
\hline $\begin{array}{l}\text { Belchite pri Zara- } \\
\text { gozi }\end{array}$ & Španija & $\begin{array}{l}\text { To je morda najbolj razširjen opomnik v Španiji na } \\
\text { uničenje v državljanski vojni leta 1937. Vas je bila } \\
\text { med spopadi popolnoma uničena. }\end{array}$ \\
\hline $\begin{array}{l}\text { Tura Jacka Raz- } \\
\text { parača, London }\end{array}$ & $\begin{array}{l}\text { Združeno } \\
\text { kraljestvo }\end{array}$ & $\begin{array}{l}\text { Zgodba serijskega morilca, ki je na ulicah Londo- } \\
\text { na brutalno umoril več prostitutk. Mediji so jo de- } \\
\text { setletja intenzivno promovirali in s tem zgradili } \\
\text { mit in turistično atrakcijo (turo). }\end{array}$ \\
\hline $\begin{array}{l}\text { Hiše Anne Frank, } \\
\text { Amsterdam }\end{array}$ & Nizozemska & $\begin{array}{l}\text { Hiša Anne Frank je bila ustanovljena kot biograf- } \\
\text { ski muzej, ki prikazuje zgodbe, ki jih je deklica na- } \\
\text { pisala v času nacistične okupacije Amsterdama. }\end{array}$ \\
\hline
\end{tabular}

Opombe Prirejeno po Fonseca idr. (2016, str. 4-5).

na nekega naroda oz. pridobijo ta status celo na širši globalni ravni, npr. nekdanje koncentracijsko taborišče Auschwitz-Birkenau, ki se je razvilo v univerzalni simbol holokavsta (White in Frew, 2013).

\section{Temačni turizem v svetu}

Številni oboroženi konflikti z večjim ali manjšim številom mrtvih, ranjenih ali kako drugače prizadetih ponujajo osnovo za razvoj temačnega turizma praktično povsod na zemeljski obli. Temu lahko dodamo še številne naravne nesreče ali druge dogodke, ki so povezani s smrtjo ali trpljenjem, npr. smrt poznanih oseb (umetnikov, državnikov ipd.). V preglednicah 3.1, 3.2 in 3.3 so zbrani nekateri mednarodno prepoznavni primeri temačnega turizma, ki so tudi zaznamovani z množičnim obiskom in jih zato lahko upravičeno obravnavamo kot reprezentativne primere temačnega turizma.

Poleg primerov, navedenih v preglednicah 3.1, 3.2 in 3.3, lahko naštejemo še nekaj drugih danes prepoznavnih primerov temačnega 
Preglednica 3.2 Izbrani primeri krajev in prireditev, povezanih s temačnim turizmom v Aziji in Afriki

\begin{tabular}{|c|c|c|}
\hline Kraj & Država & Opis \\
\hline $\begin{array}{l}\text { Spominski park } \\
\text { miru, Hirošima }\end{array}$ & Japonska & $\begin{array}{l}\text { Temelji na tragičnih posledicah jedrske bombe, } 6 \text {. } \\
\text { avgusta 1945. Osebni podatki, predstavljeni v mu- } \\
\text { zeju, so zelo vznemirjajoči in spomnijo obiskoval- } \\
\text { ce, da miru ne bi smeli jemati kot samoumevno. }\end{array}$ \\
\hline $\begin{array}{l}\text { Muzej Tuol } \\
\text { Slang, Phnom } \\
\text { Penh }\end{array}$ & Kambodža & $\begin{array}{l}\text { Nekdanje taborišče za iztrebljanje, kjer je bilo na } \\
\text { tisoče Kambodžanov ubitih. Skupaj s Polji smrti } \\
\text { temačen opomnik kamboške zgodovine druge po- } \\
\text { lovice 2o. stoletja. }\end{array}$ \\
\hline $\begin{array}{l}\text { Dharavi Slum, } \\
\text { Mumbai }\end{array}$ & Indija & $\begin{array}{l}\text { To je eden izmed najbolj obiskanih slumov na sve- } \\
\text { tu. Posebej je pridobil na "popularnosti« po sne- } \\
\text { manju filma Revni milijonar. }\end{array}$ \\
\hline $\begin{array}{l}\text { Zapor Hoa Lo, } \\
\text { Hanoi }\end{array}$ & Vietnam & $\begin{array}{l}\text { Zapor, ki so ga francoski kolonisti v Vietnamu } \\
\text { uporabljali za politične zapornike, pozneje pa tudi } \\
\text { severni Vietnam za vojne ujetnike med vietnam- } \\
\text { sko vojno. Takrat je bil ameriškim ujetnikom sar- } \\
\text { kastično znan kot »Hanoi Hilton«. }\end{array}$ \\
\hline $\begin{array}{l}\text { Gozd samomo- } \\
\text { rov, gora Fuji }\end{array}$ & Japonska & $\begin{array}{l}\text { Gozd Aokigahara je v japonski mitologiji poznan } \\
\text { po zgodovinski povezanosti z demoni in je prilju- } \\
\text { bljeno mesto za samomore. }\end{array}$ \\
\hline $\begin{array}{l}\text { Kraji bojev na } \\
\text { Galipoliju }\end{array}$ & Turčija & $\begin{array}{l}\text { Na polotoku Galipoli je v letih } 1915 \text { in } 1916 \text { padlo } \\
\text { več kot pol milijona turških, britanskih (Britanski } \\
\text { imperij) in francoskih vojakov. To je zgodovinski } \\
\text { kraj posebne pietete, ki ponuja oglede spomeni- } \\
\text { kov in grobnic. }\end{array}$ \\
\hline $\begin{array}{l}\text { Memorialni cen- } \\
\text { ter genocida v } \\
\text { Kigali }\end{array}$ & Ruanda & $\begin{array}{l}\text { Ta spomenik spominja na genocid v Ruandi, ki se } \\
\text { je zgodil leta } 1994 .\end{array}$ \\
\hline $\begin{array}{l}\text { Squatter Camp } \\
\text { Soweto }\end{array}$ & $\begin{array}{l}\text { Južna } \\
\text { Afrika }\end{array}$ & $\begin{array}{l}\text { Mesto, prežeto z zgodbo o apartheidu, je najbolj } \\
\text { obiskana atrakcija Južne Afrike. }\end{array}$ \\
\hline
\end{tabular}

Opombe Prirejeno po Fonseca idr. (2016, str. 4-5).

turizma, ki so povezani s pomembnimi dogodki v zgodovini Evropi, Slovenije ali drugi držav, nastalih na pogorišču socialistične Jugoslavije (SFRJ). Tako so danes poznani kraji na nekdanji zahodni fronti (npr. Verdun, Ypres) ali na južni/italijanski fronti (npr. Bormio, Arco, Kobarid), ki so tekom »velike vojne« terjale milijonske žrtve. Iz druge svetovne vojne je potrebno omeniti Normandijo, Berlin, Varšavski geto, pa tudi ostanke mnogih koncentracijskih taborišč po Evropi. Poleg teh, ki so mednarodno prepoznavni, je potrebno omeniti še mnogo ostalih, ki jih kot pomembne razumejo posamezni narodi, 
Preglednica 3.3 Izbrani primeri krajev in prireditev, povezanih s temačnim turizmom v Severni in Srednji Ameriki

\begin{tabular}{|c|c|c|}
\hline Kraj & Država & Opis \\
\hline $\begin{array}{l}\text { Ground Zero - } \\
\text { spomenik v spo- } \\
\text { min na 11. sep- } \\
\text { tember, New } \\
\text { York }\end{array}$ & ZDA & $\begin{array}{l}\text { V spomin skoraj } 3.000 \text { žrtvam, ubitih v teroristič- } \\
\text { nih napadih 11. septembra } 2001 \text { na Svetovni trgo- } \\
\text { vinski center. }\end{array}$ \\
\hline $\begin{array}{l}\text { Zvezni zapor v } \\
\text { Alcatrazu }\end{array}$ & $\mathrm{ZDA}$ & $\begin{array}{l}\text { To je bil močno varovan zapor na otoku Alcatraz. } \\
\text { Tu so bili zaprti tisti, ki so nenehno povzročali te- } \\
\text { žave v drugih zveznih zaporih in tudi nekaj najve- } \\
\text { čjih ameriških kriminalcev. }\end{array}$ \\
\hline $\begin{array}{l}\text { Arlington Nati- } \\
\text { onal Cemetery, } \\
\text { Virginia }\end{array}$ & ZDA & $\begin{array}{l}\text { Vojaško pokopališče na } 624 \text { hektarjih, kjer so po- } \\
\text { kopane žrtve ameriške državljanske vojne pa tudi } \\
\text { predhodnih vojn. }\end{array}$ \\
\hline $\begin{array}{l}\text { Državni spome- } \\
\text { nik in muzej, } \\
\text { Oklahoma City }\end{array}$ & ZDA & $\begin{array}{l}\text { Spomenik v čast žrtvam, preživelim, reševalcem } \\
\text { in vsem, ki so bili prizadeti v bombnem napadu v } \\
\text { Oklahoma Cityju 19. aprila 1995. }\end{array}$ \\
\hline Otok lutk & Mehika & $\begin{array}{l}\text { Na otoku je več sto zastrašujočih lutk. Njihove raz- } \\
\text { rezane okončine, obglavljene glave z izpraznjeni- } \\
\text { mi očmi »krasijo« drevesa. To je eno najgrozljivej- } \\
\text { ših/najstrašljivejših mest na svetu. }\end{array}$ \\
\hline
\end{tabular}

Opombe Prirejeno po Fonseca idr. (2016, str. 4-5).

ne dosegajo pa mednarodne prepoznavnosti. ${ }^{5}$ Zaradi geografske bližine in tudi neposredne vpletenosti je potrebno izpostaviti t.i. balkanski konflikt $\mathrm{v}$ devetdesetih letih 20. stoletja, povezan $\mathrm{z}$ razpadom SFRJ. Razmah krvavega konflikta je imel na Hrvaškem in v Bosni in Hercegovini izjemno tragične posledica. Danes obstajajo v regiji kraji, ki jih je politika skupaj z mediji povzdignila v nacionalni mit, npr. Vukovar in Srebrenica; v smislu razvoja mednarodnega temačnega turizma pa ti primeri ne dosegajo večjih uspehov (vprašljiva je promocija, turistična infrastruktura ipd.). Med progresivnejšimi v tej smeri sta Sarajevo in deloma tudi Mostar, saj so tam ustrezni muzeji in druge antropogene atrakcije, tematski nastanitveni obrati, organizirani skupinski ogledi oz. ture po mestih (glej sliko 3.1) ipd. Čeprav so ti primeri zaradi kratke časovne odmaknjenosti in težavne postkonfliktne situacije v družbi precej težavni in tudi etično sporni, pa

5. Kot primer lahko navedemo številne spomenike in spominske prireditve (komemoracije), povezane z drugo svetovno vojno, ki se tekom celega leta organizirajo praktično na celotnem ozemlju Slovenije. 
Slika 3.1

Promocijski letak za tematsko turo v Sarajevu za tuje turiste

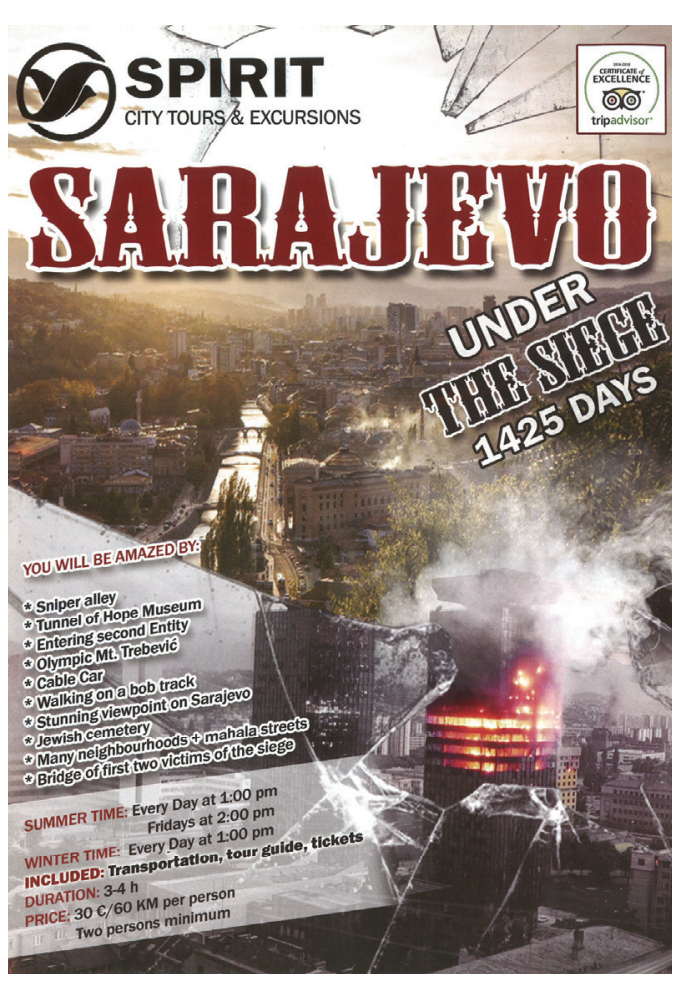

65

po drugi strani omogočajo pridobivanje prihodkov domačinom, ki imajo sicer omejene možnosti zagotavljanja eksistence z drugim delom.

\section{Temačni turizem v Sloveniji}

Pri opredeljevanju razvitosti in prepoznavnosti temačnega turizma $\mathrm{v}$ Sloveniji, se je smotrno nasloniti na glavne konflikte 20. stoletja in s tem povezano dediščino, vključno s prireditvami, kakršne so komemoracije.

\section{Temačni turizem in dediščina "velike vojne"}

Dvanajst bitk soške fronte (med letoma 1915 in 1917) je bilo v splošnem med pomembnejšimi, ki so se odvile med "veliko vojno" (Gosar idr., 2015; Klavora, 2011), in so bile tudi najbolj krvavi spopad na ozemlju (današnje) Slovenije. Posledično je na območju od Tržaškega zaliva preko kraške planote in spodnje Vipavske doline do celotne doline Soče mogoče najti številna vojna spominska obeležja in druge ostanke vojne. Začetki organiziranega razvoja temačnega turizma 
(kot ga razumemo danes) v tem delu Slovenije segajo v obdobje italijanskega fašizma (Kavrečič, 2017; Todero, 2010). Še posebej zanimiv je primer pokopališča v Logu pod Mangartom, kjer so pokopani Bošnjaki. Islamska skupnost v Sloveniji je leta $2007 \mathrm{z}$ dovoljenjem Zavoda za varstvo kulturne dediščine Slovenije - Območnega urada Nova Gorica križe na grobovih zamenjala z muslimanskimi nagrobniki (Zamenjani križi $v$ Logu pod Mangartom, 2007).

Poleg mitraljeznih in topniških položajev ter mreže jam in jarkov - npr. Kolovrat, muzej prve svetovne vojne na prostem - sta v naravnem okolju doline postavljena dva zelo prepoznavna primera sakralnih zgradb: (a) Javorca, spominska cerkev Svetega Duha (ki jo je leta 1916 zgradila avstro-ogrska vojska), (b) Ruska kapelica pod prelazom Vršič pri Kranjski Gori (ki so jo leta 1916 zgradili ruski ujetniki) je postala simbol prijateljstva in kraj spomina ter letnih srečanj oblasti držav in cerkva (in drugih javnosti) Slovenije in Rusije.

Kobariški muzej, ki je bil leta 1993 uvrščen med finaliste za nagrado Evropski muzej leta, je eden najreprezentativnejših razstavljavcev dediščine. Muzej je povezan s svetovno vojno in je istega leta prejel muzejsko nagrado Sveta Evrope, kar jasno kaže na njegovo mednarodno prepoznavnost in pomen. Svoj vlogo in pomen v Posočju, kot tudi širše v nacionalnem ali celo srednjeevropskem prostoru, izkazuje še danes, ko je s približno 64.000 obiskovalci letno ${ }^{6}$ med najbolj obiskanimi muzeji v Sloveniji, a se na drugi strani vseeno težko primerja s tistimi najreprezentativnejšimi primeri temačnega turizma na globalnem nivoju (Šuligoj in Jovanović, 2019, str. 98). Danes so torej območja bivših bojišč »velike vojne « zgledni primeri, ki promovirajo mir, spomin, imajo pa tudi izobraževalno noto; dediščina soške fronte je zanimiva za turiste vseh vpletenih narodnosti: od srednjeevropskih in balkanskih narodov do Italijanov in njihovih zahodnih zaveznikov. Posočje je danes v mednarodnem prostoru poznano kot destinacija temačnega turizma (najbolj poznana tovrstna turistična destinacije v Sloveniji), kjer Fundacija Poti miru v Posočju od leta 2000 dalje ponuja vso znanstveno, strokovno in promocijsko podporo. ${ }^{7}$

Pomembno priznanje, ki bo pripomoglo k nadaljnji uveljavitvi dediščine prve svetovne vojne $\mathrm{v}$ mednarodnem prostoru, je podelitev

6. Podatek velja za leto 2017 .

7. Več o tem je mogoče najti na http://www.potmiru.si/. 


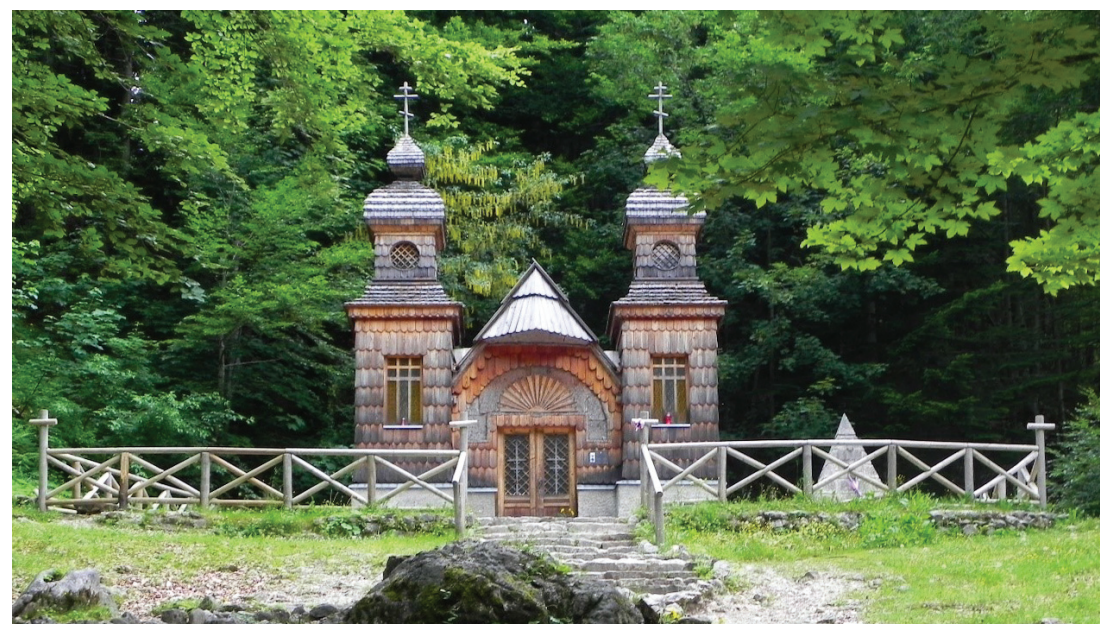

Slika 3.2 Ruska kapelica (foto Metod Šuligoj)

Znaka evropske dediščine že omenjeni cerkvi Sv. Duha na Javorci leta 2018. ${ }^{8}$ Leseni cerkvi, ki je izjemen sakralni objekt in arhitekturni biser, je bilo tako priznana še njena memorialna in civilizacijska vrednost.

Drugi pomembni sakralni objekt je Ruska kapelica pod Vršičem (slika 3.2), ki je s spominskimi srečanji postala nekakšen simbol dobrih odnosov med Slovenijo in Rusijo.

\section{Temačni turizem in dediščina druge svetovne vojne}

Leta 2016 je v Muzeju moderne umetnosti v Ljubljani gostovala potujoča razstava "Po cestah revolucije. Spominski turizem v socialistični Jugoslaviji.$^{9}$ Razstava je predstavila memorialni turizem kot segment turizma v SFRJ. To je bil povojni družbeni fenomen, ki je s svojimi umetniškimi, arhitekturnimi in urbanističnimi dosežki zagotovo pomembno oblikoval memorialno in drugo dediščino SFRJ. Vse te stvaritve - memorialna dediščina narodnoosvobodilnega boja s simbolično, zgodovinsko in družbeno-politično razsežnostjo so bile očitno tudi komercializirane in s tem del memorialnega ali

8. The European Heritage Label se podeli krajem, ki so igrali pomembno vlogo v evropski zgodovini ali v procesu nastajanja Evropske unije.

9. Pripravili so jo naslednji projektni partnerji: sF:ius - Socijalni rub: zanimljive neispričane priče (Zagreb), Grupa arhitekata (Beograd), Moderna galerija MG+MsuM (Ljubljana), Historijski muzej BiH (Sarajevo). 
temačnega turizma. Posledično celotno območje današnje Slovenije, ene od držav naslednic nekdanje SFRJ, ponuja veliko spominskih krajev lokalnega, regionalnega ali državnega pomena.

Ne glede na to pa je dediščina druge svetovne vojne še danes razumljena zelo različno. Zaradi nekaterih nasilnih (revolucionarnih) ravnanj komunističnega režima med in takoj po vojni je mogoča tudi negativna interpretacija vojnega ter povojnega obdobja in s tem povezane dediščine. Kljub vsem negativnim interpretacijam je v Sloveniji še vedno močan poudarek na spominu in ohranjanju spomina na drugo svetovno vojno, na njene žrtve in junake. Za razliko od drugih držav naslednic SFRJ je dediščina, povezana z drugo svetovno vojno, v Sloveniji veliko bolj ohranjena in je $\mathrm{v}$ mnogih primerih vključena v tradicionalne prireditve. ${ }^{10}$ Vsakega 1 . novembra, ob pomembnih državnih praznikih in drugih pomembnih dneh se ob spomenikih odvijajo komemoracije/proslave, npr. v spominskem parku borcev Ix. korpusa na Kobilniku ob Trnovem pri Gorici, na Osankarici (v spomin na padec pohorskega bataljona) ali v Dražgošah v spomin na pokol domačinov in uničenje vasi Dražgoše s strani nacistov. ${ }^{11} \mathrm{~V}$ zadnjem primeru je vsako leto januarja organiziran tudi spominski deseturni nočni pohod v dolžini $25 \mathrm{~km}$. Tako je tragični zgodovinski dogodek smiselno povezan z današnjo športno prireditvijo, ki privablja udeležence vseh generacij. Podoben pristop je zaznan tudi v Ljubljani, kjer je vsako leto maja organiziran pohod ob žici (»Pot ob žici«) v spomin na obdobje, ko so mesto zasedli in ogradili italijanski fašisti.

Podobno je bil v začetku osemdesetih let prejšnjega stoletja izveden tudi prvi kolesarski Maraton Franja (Ljubljana-Cerkno) v spomin na znano partizansko bolnišnico Franjo, a zgodovinsko ozadje te športne prireditve vseeno ni primerljivo z ozadji predhodno navedenih primerov - bolnišnica Franja ali zdravnica Franja BojcBidovec namreč s to športno prireditvijo nista neposredno povezani. Vsekakor prireditve in kraji spomina na drugo svetovno vojno niso mednarodno prepoznavni in privlačni turistični proizvodi, kot je tisti, ki smo ga predstavlili v primeru dediščine, povezane s prvo sve-

10. Več o tem je mogoče najti v Razaranje jugoslavenske kulture (2014) in Bandur (2017).

11. Vzdušje je zelo zanimivo, saj udeleženci vseh starosti hodijo z baklami, zastavami in mnogi nosijo na glavi partizansko kapo imenovano titovka ali triglavka. 
tovno vojno. Največja izjema je verjetno ravno partizanska bolnišnica Franja, ki je leta 2015 prejela Znak evropske dediščine. ${ }^{12}$

\section{Temačni turizem in ostala memorialna dediščina 20. stoletja}

Memorialna dediščina poznega 20. stoletja na Slovenskem ni posledica večjih vojn ali/in mednarodnih spopadov. Leta 1991 se je ravno v Sloveniji, nekdanji republiki SFRJ, začel t.i. balkanski konflikt v devetdesetih, ki pa je na slovenskem ozemlju trajal le nekaj dni - v obliki t. i. desetdnevne vojne. Glavna (vojaška) žarišča so bila:

- na cesti Zagreb (Karlovac)-Ljubljana,

- na meji z Italijo in Avstrijo in

- v posameznih vojašnicah, npr. v Ormožu, ali na strateških točkah, npr. na Nanosu, Kumu.

V primerjavi s spopadi na Hrvaškem, v Bosni in Hercegovini ali na Kosovu je imela Slovenija malo žrtev in le nekaj škode na infrastrukturi. Klub temu so bili na mnogih mestih postavljeni spomeniki ali spominske plošče. Uporabljene so bile tehnične (betonske) tehnične ovire za tanke in druga vojaška vozila, ki jih ni bilo mogoče uporabiti za druge namene.

Spomeniki in druga obeležja, povezana z osamosvojitveno vojno, $\mathrm{v}$ turističnem smislu nimajo pomembne vrednosti; $\mathrm{z}$ vidika mednarodnega turizma ta mesta še zdaleč niso prepoznavna. Podoben primer pomanjkanja valorizacije in turistične eksploatacije je tudi zapuščina množičnih povojnih pobojev, čeprav je bilo v zadnjih letih v Sloveniji izvedeno sistematično raziskovanje pobojev in je bilo posledično ugotovljenih veliko lokacij - ugotovljenih je bilo 600 lokacij prikritih grobišč (Ferenc, 2012) ${ }^{13} \mathrm{~V}$ obdobju SFRJ niso bile dovoljene preiskave, prenašanje posmrtnih ostankov žrtev, označevanje ali obisk teh grobišč (Ferenc, 2012), in čeprav je danes vse to mogoče, je ta tema v Sloveniji še vedno sporna. Ti zgodovinski dogod$\mathrm{ki} /$ kraji travmatizirajo in delijo tako slovensko kot tudi postsocialistično družbo drugih držav bivše SFRJ.

12. Posebej bi bilo potrebno preveriti, kako tuji pa tudi domači udeleženci dojemajo "spominske športne prireditve«.

13. Slovenija je edina država bivše SFRJ, ki te poboje (sistematično) preiskuje vse od leta 1991 dalje; je tudi edina država, ki je simbolično pokopala žrtve, ne glede na njihovo narodnost. Prvi pokop je bil izveden že leta 1991 (Ferenc, 2012). 


\section{Zaključek}

Sodobni temačni turizem vključuje pester izbor destinacij na globalni ravni. Vedno nove "temne destinacije«, kot žalostni odraz današnje družbene realnosti, niso pomembne zgolj s turističnega vidika, ampak tudi, ker lokalnemu prebivalstvu na postkonfliktnih območjih omogočajo izvajanje pridobitnih dejavnosti. So pa po drugi strani te iste okoliščine lahko tudi etično sporne, saj odpirajo stare rane in dehumanizirajo žrtve.

Čeprav je ta specifična oblika turizma zanimiva le določenemu segmentu turistov, lahko opazimo, da »temne atrakcije« obiskujejo različni profili obiskovalcev. Vse temne atrakcije niso enake, saj so nekatere temnejše kot druge, avtentičnejše in nudijo intenzivnejše čustveno doživetje/izkušnjo. Takšni primeri tematske ponudbe so tudi v Sloveniji. Slovenija je s tovrstno ponudbo tudi mednarodno prepoznavna. Trije primeri dediščine - partizanska bolnišnica Franja, spominska cerkvica Javorca in pokopališki kompleks Žale arhitekta Jožeta Plečnika - so do vključno leta 2019 prejeli znak evropske kulturne dediščine. Vse tri lahko umestimo v segment temačnega turizma, čeprav ima predvsem zadnji nekoliko drugačen pomen. $V$ formalnem smislu ti primeri (memorialne) dediščine dopolnjujejo tiste iz Slovenije, ki so uvrščene na listo unesca. Pri tem je potrebno biti pozoren na pretirano komercializacijo, ki lahko ogrozi avtentične ostanke preteklih konfliktov. Sodobne uprizoritve (simulacije) preteklih spopadov, so zelo zanimive za današnje obiskovalce, ki si lahko na tak način ustvarijo boljšo sliko o tem, kako je nek spopad potekal, vidijo (otipajo, uporabijo) uniforme, orožje in podobno. Takšna izvedba (prireditev) mora biti ustrezno strokovno podprta, strokovno vodena ter sam program ustrezno interpretiran. Podobno velja za razne makete, dokumentarne posnetke/filme in druge sodobne interaktivne prezentacije v muzejih ter spominskih centrih, ki želijo ustvarjati razmere za podoživljanje preteklosti. Izhajati je potrebno iz spominskega in edukacijskega pomena teh krajev, prireditev in povezanih doživetij, ki pa niso (ne smejo biti) povezani z zabavo. V tem kontekstu je potrebno pri razvoju postopati bolj premišljeno, tudi konzervativno, da se izognemo napačnim interpretacijam, morebitnim zlorabam, okoriščanju s trpljenjem drugih ${ }^{14}$ ter da zaščitimo spomin

14. Tukaj ne mislimo na ponudbo nastanitvenih kapacitet, hrane in pijače ipd., ki so nujne za razvoj. 
na pretekle dogodke in dostojanstvo žrtev. To pomeni, da mora biti bodoči razvoj drugačen, kot to velja za druge oblike turizma. Vsekakor mora upoštevati rezultate multidisciplinarnih raziskav, ki morajo obsegati primere kritičnih obravnav dobrih in neprimernih praks ter obravnave vloge in percepcije lokalnega prebivalstva, svojcev žrtev, vojnih veteranov in invalidov, zgodovinskega ozadja, destinacijskih organizacij in ponudnikov turističnih storitev ter uporabe sodobnih informacijskih/tehničnih rešitev za izboljšanje možnosti predstavitve/interpretacije memorialne dediščine mednarodnim obiskovalcem.

Na območju Slovenije so eno izmed širših družbenih vprašanj prav gotovo povojni poboji (na Primorskem fojbe), ki imajo tudi turistični potencial, a je težko pričakovati, da bi v bližnji prihodnosti te potenciale lahko uresničili, pa čeprav bi morda rezultati raziskav to nakazovali. Pravzaprav bi Slovenija s tem postala reprezentativni primer temačnega turizma v Evropi, kjer bi lahko obiskovalcem pokazali tragične posledice obeh svetovnih konfliktov, nekaj tudi s področja zadnjega balkanskega konflikta (razpad SFRJ), kot tudi posledice vseh treh avtoritarnih/totalitarnih družbenih sistemov 20. stoletja.

\section{Literatura}

Ali-Knight, J. M. (2011). The role of niche tourism products in destination development [neobjavljena doktorska disertacija]. Napier University.

Ashworth, G., in Isaac, R. K. (2015). Have we illuminated the dark? Shifting perspectives on 'dark' tourism. Tourism Recreation Research, 40(3), 316-325.

Baldwin, F., in Sharpley, R. (2009). Battlefield tourism: Bringing organised violence back to life. V R. Sharpley in P. R. Stone (ur.), The darker side of travel: The theory and practice of dark tourism (str. 186-216). Channel View Publications.

Bandur, S. (2017, 30. april). Ne več množično obiskani, povsem pozabljeni pa tudi ne. Delo, 17.

Beech, J. (2000). The enigma of holocaust sites as tourist attractions: The case of Buchenwald. Managing Leisure, 5(1), 29-41.

Bigley, J. D., Lee, C.-K., Chon, J., in Yoon, Y. (2010). Motivations for warrelated tourism: A case of DMz visitors in Korea. Tourism Geographies, 12(3), 371-394.

Biran, A., Poria, Y., in Oren, G. (2011). Sought experiences at (dark) heritage sites. Annals of Tourism Research, 38(3), 820-841. 
Blom, T. (2000). Morbid tourism: A postmodern market niche with an example from Althorp. Norsk Geografisk Tidsskrift, 54(1), 29-36.

Bristow, R. S., in Newman, M. (2005). Myth vs. fact: An exploration of fright tourism. V K. Bricker (ur.), Proceedings of the 2004 Northeastern Recreation Research Symposium, 215-221. us Department of Agriculture.

Butcher, J. (2003). The moralisation of tourism: Sun, sand ... and saving the world? Routledge.

Causevic, S., in Lynch, P. (2011). Phoenix tourism: Post-conflict role. Annals of Tourism Research, 38(3), 780-800.

Clark, L. B. (2006). Placed and displaced: Trauma memorials. V L. Hill in H. Paris (ur.), Performance and place (str. 129-138). Palgrave Macmillan.

Drvenkar, N., Banožić, M., in Živić, D. (2015). Development of memorial tourism as a new concept: Possibilities and restrictions. Tourism and Hospitality Management, 21(1), 63-77.

Dunkley, R. A., Morgan, N., in Westwood, S. (2007). A shot in the dark? Developing a new conceptual framework for thanatourism. Asian Journal of Tourism and Hospitality Research, 1(1), 54-63.

Dunkley, R., Morgan, N., in Westwood, S. (2011). Visiting the trenches: Exploring meanings and motivations in battlefield tourism. Tourism Management, 32(4), 860-868.

Đurašević, S. (2014). Thematic tourism as an important segment in the business of modern tour operators. Turističko poslovanje, 13, 109-117.

Fallon, P., in Robinson, P. (2016). 'Lest we forget': A veteran and son share a 'warfare tourism' experience. Journal of Heritage Tourism, 12(1), 2135.

Ferenc, M. (2012). Prekopi žrtev iz prikritih grobišč (1991-2011). Znanstvena založba Filozofske fakultete.

Foley, M., in Lennon, J. J. (1996). JFK and dark tourism: A fascination with assassination. International Journal of Heritage Studies, 2(4), 198-211.

Fonseca, A. P., Seabra, C., in Silva, C. (2016). Dark tourism: Concepts, typologies and sites. Journal of Tourism Research \& Hospitality, 2, 1-6.

Gibson, D. C. (2006). The relationship between serial murder and the American tourism industry. Journal of Travel \& Tourism Marketing, $20(1), 45-60$.

Gosar, A., Koderman, M., in Rodela, M. (ur.). (2015). Dark tourism: PostWWI destinations of human tragedies and opportunities for tourism development; Proceedings of the international workshop. University of Primorska.

Hertzog, A. (2012). War battlefields, tourism and imagination. Via-Tourism Review, 1. https://doi.org/10.400o/viatourism.1283 
Jamal, T., in Lelo, L. (2010). Exploring the conceptual and analytical framing of dark tourism: From darkness to intentionality. V R. Sharpley in P. Stone (ur.), Tourist experience: Contemporary perspectives (str. 29-42). Routledge.

Kavrečič, P. (2017). „Sacro pellegrinaggio«: Visits to World War I memorials on the Soča/Isonzo front in the interwar period. Etnološka Tribina: Journal of Croatian Ethnological Society, 47(40), 141-160.

Kendle, A. (2008, 24. januar). Dark tourism: A fine line between curiousity and exploitation. Vagabondish. http://www.vagabondish.com/dark -tourism-travel-tours/

Kennell, J., Šuligoj, M., in Lesjak, M. (2018). Dark events: Commemoration and collective memory in the former Yugoslavia. Event Management, 22(6), 945-963.

Keyes, M. (2012). War tourism: Shaping memory and perception in postwar Vietnam. Summer Research, (164). https://soundideas .pugetsound.edu/summer_research/164

Klavora, V. (2011). Škabrijel: Soška fronta 1917. Mohorjeva.

Knox, D. (2006). The sacralised landscapes of Glencoe: From massacre to mass tourism, and back again. International Journal of Tourism Research, 8(3), 185-197.

Kravanja, B. (2018). Dediščina soške fronte kot izhodišče za razmislek o sodobnih pristopih k dediščinski politiki. Etnolog: glasnik Slovenskega etnografskega muzeja, 28, 105-122.

Kužnik, L., in Veble, N. (2017). Memento mori - identifikacija temačnih zgodb pokopališč v občinah Brežice in Krško kot podlaga za razvoj temačnega turizma. Glasnik Slovenskega etnološkega društva, 57(3/4), 99-109.

Lemelin, H., Dawson, J., Stewart, E. J., Maher, P., in Lueck, M. (2010). Lastchance tourism: The boom, doom, and gloom of visiting vanishing destinations. Current Issues in Tourism, 13(5), 477-493.

Lennon, J., in Foley, M. (2000). Dark tourism: The attraction of death and disaste. Cengage Learning.

Light, D. (2017). Progress in dark tourism and thanatourism research: An uneasy relationship with heritage tourism. Tourism Management, 61, 275-301.

Mansfeld, Y., in Korman, T. (2015). Between war and peace: Conflict heritage tourism along three Israeli border areas. Tourism Geographies, 17(3), 437-460.

Razaranje jugoslavenske kulture: U Hrvatskoj uništeno 300 spomenika мов- $a$. (2014, 30. marec). Index.hr. http://www.index.hr/vijesti/ clanak/razaranje-jugoslavenske-kulture-u-hrvatskoj-unisteno -300o-spomenika-noba/736936.aspx

Rojek, C. (1994). Ways of escape. Rowman \& Littlefield. 
Rolfes, M. (2010). Poverty tourism: Theoretical reflections and empirical findings regarding an extraordinary form of tourism. GeoJournal, 75(5), 421-442.

Seaton, A. V. (1996). Guided by the dark: From thanatopsis to thanatourism. International Journal of Heritage Studies, 2(4), 234-244.

Seaton, A. V. (1999). War and thanatourism: Waterloo 1815-1914. Annals of Tourism Research, 26(1), 130-158.

Seaton, T. (2009). Thanatourism and its discontents: An appraisal of a decade's work with some future issues and directions. V T. Jamal in M. Robinson (ur.), The Sage handbook of tourism studies (str. 522543). Sage.

Seaton, T. (2018). Encountering engineered and orchestrated remembrance: A situational model of dark tourism and its history. V P. R. Stone, R. Hartmann, T. Seaton, R. Sharpley, in L. White (ur.), The Palgrave handbook of dark tourism studies (str. 9-31). Palgrave Macmillan.

Smith, V. L. (1998). War and tourism: An American ethnography. Annals of Tourism Research, 25(1), 202-227.

Stone, P. R. (2006). A dark tourism spectrum: Towards a typology of death and macabre related tourist sites, attractions and exhibitions. Turizam, 54(2), 145-16o.

Stone, P., in Sharpley, R. (2008). Consuming dark tourism: A thanatological perspective. Annals of Tourism Research, 35(2), 574-595.

Šligoj, M. (2016a). Impact of the Great war on the conditions for the development of the hospitality industry in Gorizia/Görz/Gorica and its surroundings. Historický časopis, 64(3), 431-449.

Šuligoj, M. (2016b). Memories of war and warfare tourism in Croatia. Annales: Series Historia et Sociologia, 26(2), 259-270.

Šuligoj, M. (2017). Warfare tourism: An opportunity for Croatia? Economic Research, 30(1), 439-452.

Šuligoj, M., in Jovanović, T. (2019). Education for dark tourism: Some contemporary facts and issues. V J. Gržinić, M. Kostić-Bobanović, in D. M. Currie (ur.), Tourism education in an age of change (str. 93-113). Juraj Dobrila University of Pula.

Tarlow, P. (2005). Dark tourism: The appealing "dark « side of tourism and more. V M. Novelli (ur.), Niche tourism: Contemporary issues, trends and cases (str. 47-58). Elsevier.

Todero, F. (2010). Politiche della memoria della Grande guerra: Il caso della Venezia Giulia. Acta Histriae, 18(3), 383-398.

Trauer, B. (2006). Conceptualizing special interest tourism: Frameworks for analysis. Tourism Management, 27(2), 183-200.

Tunbridge, J. E., in Ashworth, G. J. (1996). Dissonant heritage: The management of the past as a resource in conflict. Wiley. 
White, L., in Frew, E. (2013). Dark tourism and place identity: Managing and interpreting dark places. Routledge.

Winter, C. (2009a). The shrine of remembrance Melbourne: A short study of visitors' experiences. International Journal of Tourism Research, 11(6), 553-565.

Winter, C. (2009b). Tourism, social memory and the Great War. Annals of Tourism Research, 36(4), 607-626.

Winter, C. (2011). Battlefield visitor motivations: Explorations in the great war town of Ieper, Belgium. International Journal of Tourism Research, 13(2), 164-176.

Wise, N. A. (2011). Post-war tourism and the imaginative geographies of Bosnia and Herzegovina, and Croatia. European Journal of Tourism Research, 4(1), 5-24.

Wise, N., in Mulec, I. (2014). Semblances of 'war tourism' in Sarajevo, post-2005. American Journal of Tourism Management, 3(18), 1-9.

World Tourism Organization. (1985). The role of recreation management in the development of active holidays and special interest tourism and consequent enrichment of the holiday experience.

Young, C., in Light, D. (2016). Interrogating spaces of and for the dead as 'alternative space': Cemeteries, corpses and sites of dark tourism. International Review of Social Research, 6(2), 61-72.

Zamenjani križi v Logu pod Mangartom. (2007, avgust 18). Islamska skupnost v Republiki Sloveniji. https://www.islamska-skupnost.si/ novice/2007/o8/zamenjani-krii-v-logu-pod-mangartom/ 